\title{
EDUCAÇÃO DE JOVENS E ADULTOS E EDUCAÇÃO PROFISSIONAL NO BRASIL: CAMINHOS E DESCAMINHOS NO CONTEXTO DA DIVERSIDADE
}

\author{
M. A. AZEVEDO* e A. M. B. N. TAVARES \\ Instituto Federal de Educação, Ciência e Tecnologia do Rio Grande de Norte \\ marcio.azevedo@ifrn.edu.br*
}

Artigo submetido em julho/2015 e aceito em julho/2015

DOI: $10.15628 /$ holos.2015.3182

\section{RESUMO}

$\mathrm{O}$ artigo discute a educação de jovens e adultos e a educação profissional no âmbito de expansão dos Institutos Federais, nomeadamente na região do Mato Grande norte-rio-grandense, marcada por uma ampla diversidade política, socioeconômica e cultural. Resulta de pesquisa fomentada pelo CNPq, a qual mapeou e levantou indicadores acerca de ofertas, programas e projetos, como o ProJovem Campo e o Brasil Alfabetizado, tendo como público-alvo jovens e adultos pouco escolarizados ou em busca de qualificação profissional. A realização do estudo mostra que a maioria dos projetos e programas ofertados têm caráter compensatório, geralmente não têm acompanhamento pedagógico e funcionam em condições precárias. Por outro lado, a implantação de um Campus do IFRN ampliou as possibilidades de acesso à educação com qualidade e perspectivas de inserção no mundo do trabalho.

PALAVRAS-CHAVE: Educação de jovens e adultos, educação profissional, programas e projetos, contexto da diversidade.

\section{YOUTH AND ADULT EDUCATION AND VOCATIONAL EDUCATION IN BRAZIL: TRACKS AND SIDETRACKS IN THE CONTEXT OF DIVERSITY}

\begin{abstract}
The article discusses the education of youth and adults and vocational education under expansion of the Federal Institutes, including in the region of Mato Grande North Rio Grande, marked by a wide diversity policy, socioeconomic and cultural. Results of research promoted by CNPq, which mapped and raised indicators about offers, programs and projects, such as Projovem field and the Literate Brazil, with the young audience and
\end{abstract}

adults with little schooling or seeking professional qualification. The completion of the study shows that most projects and programs offered have compensatory, generally do not have pedagogical support and work in poor conditions. Furthermore, the implementation of a Campus IFRN expanded the opportunities for access to quality education and integration prospects in the workplace.

KEYWORDS: Youth and adults, vocational education, programs and projects, the context of diversity. 


\section{INTRODUÇÃO}

$\mathrm{O}$ artigo discute a educação de jovens e adultos e a educação profissional no âmbito de expansão dos Institutos Federais, nomeadamente na região do Mato Grande norte-rio-grandense, marcada por uma ampla, diversa e contraditória realidade política, socioeconômica e cultural. Resulta de pesquisa fomentada pelo Conselho Nacional de Desenvolvimento Científico e Tecnológico - CNPq, a qual mapeou e levantou indicadores acerca de ofertas, programas e projetos, como o ProJovem Campo e o Brasil Alfabetizado, tendo como público-alvo os jovens e adultos pouco escolarizados, bem como aqueles que buscam qualificação profissional.

\subsection{Caminhos e descaminhos: para situar}

A partir dos anos de 1990, sobretudo a partir da Conferência Mundial de Educação para Todos, em Jomtien, os signatários desse evento comprometeram-se em instituir um conjunto de medidas de cunho reformista, as quais se desdobraram, entre outros exemplos no Brasil, na aprovação da LDB - Lei 9.394/96 (BRASIL, 1996), cuja essência não traduziu o que a sociedade brasileira vinha discutindo na agenda da política educacional. Analisando os estudos de Gajardo (1999) e de Azevedo e Silva (2012), identificamos que a reforma educativa refletiu os diversos compromissos firmados com o Banco Mundial e com o Banco Interamericano de Desenvolvimento (BID), estando explícitas as orientações de cunho neoliberal.

Nessa perspectiva, os estudos de Moura (2006) ressaltam que a educação profissional foi enquadrada na chamada dualidade entre o ensino médio e a educação profissional. Enquanto o ensino médio encontra-se na esfera - última etapa - da educação básica, a educação profissional encontra-se em capítulo distinto. Assim sendo,

Como a educação brasileira é estruturada na nova LDB em dois níveis - educação básica e educação superior, e a educação profissional não está em nenhum dos dois, consolida-se a dualidade de forma bastante explícita. [...] algo que vem em paralelo ou como um apêndice e, na falta de uma denominação mais adequada, resolveu-se tratá-la como modalidade, o que efetivamente não é correto (MOURA, 2006, p. 15-16).

Para o autor, a separação entre o ensino médio e a educação profissional foi objeto de interesse político no governo de Fernando Henrique Cardoso. O Projeto de Lei no 1603 já indicava essa tendência, mesmo antes da LDB. Em face de intensos e tensos debates, o PL no 1603 foi traduzido para alguns artigos da LDB, conforme ressalta Moura (2006), além de ficar condicionado a decretos, sendo os mais evidentes o Decreto no 2.208/97 e o 5.154/2004 .

O Instituto Federal de Educação, Ciência e Tecnologia do Rio Grande do Norte (IFRN) foi criado por meio da Lei no. 11.892, de 29 de dezembro de 2008, estando vinculado ao Ministério da Educação. Possui natureza jurídica de autarquia, sendo detentor de autonomia administrativa, patrimonial, financeira, didático-pedagógica e disciplinar (BRASIL, 2011). O IFRN é uma Instituição de educação básica, profissional, superior, pluricurricular e multicampi, sendo responsável pela oferta de educação profissional e tecnológica em diferentes níveis e modalidades de ensino, com base na conjugação de conhecimentos técnicos e tecnológicos em suas práticas pedagógicas. 
No que se refere à regulação, à avaliação e à supervisão da instituição e dos cursos de educação superior, o IFRN equipara-se às universidades federais, propondo uma articulação de ofertas da educação básica e superior (graduação e pós-graduação) à educação profissional. Assim sendo, o processo formativo visa à construção de vínculos em diferentes níveis e modalidades de ensino, buscando metodologias que estabeleçam a indissociabilidade entre o ensino, a pesquisa e a extensão.

Logo, ao se propor a superação da dissociação da "[...] ciência/tecnologia e teoria/prática, na investigação como princípio educativo e científico, nas ações de extensão como forma de diálogo permanente com a sociedade, revela[-se] sua decisão de romper com um formato consagrado, por séculos, de lidar com o conhecimento de forma fragmentada" (PACHECO, 2010, p. 23).

Conforme explicita a Lei no. 11.892, de 29 de dezembro de 2008, cabe aos Institutos Federais o compromisso de garantir $20 \%$ de suas matrículas em cursos de licenciaturas, devendo o processo de formação docente propiciar aos estudantes oportunidades de vivenciarem situações de aprendizagem de maneira a construir um perfil profissional adequado à formação de professores para atuarem na educação básica, inclusive na modalidade de educação de jovens e adultos - EJA, integrada à educação profissional, e no ensino médio integrado, sobretudo porque as suas ofertas ocorrem também no próprio IFRN.

A educação de jovens e adultos no Brasil é reconhecida como modalidade educativa, conforme dispõe a Lei de Diretrizes e Bases da Educação Nacional (LDB no 9.394/96), respaldandose, de um lado, no marco legal, estabelecido a partir dos anos de 1980, com a Constituição Federal, e, de outro, no conjunto de ações governamentais materializadas em programas e projetos. Além de se constituir como modalidade educativa vinculada aos sistemas oficiais de educação, de acordo com Gadotti (2001), podemos identificar a educação de adultos não formal geralmente vinculada a organizações não governamentais, igrejas, partidos políticos, entre outros, bem como a educação popular, resultado do "[...] processo sistemático de participação na formação, fortalecimento e instrumentalização das práticas e dos movimentos populares, com o objetivo de apoiar a passagem do saber popular ao saber orgânico" (GADOTTI, 2001, p. 30).

No que diz respeito ao marco legal para a educação de jovens e adultos no Brasil, percebemos que a Constituição Federal de 1988, também intitulada de Constituição Cidadã, dispõe sobre a educação como direito e obrigatoriedade escolar, refletindo-se na legislação educacional brasileira. Isso foi importante porque recuperou o conceito de educação como direito público subjetivo, abandonado desde a década de 1930, conforme enfatiza Paiva (2009). Isso foi ratificado pela Lei de Diretrizes e Bases da Educação Nacional (BRASIL, 1996), a qual reiterou o direito à educação, os direitos constitucionais para a população jovem e adulta (art. 4ㅇ). Ademais, a educação de jovens e adultos, de acordo com a LDB, é uma modalidade da educação básica, nos seus níveis fundamentais e médio, sendo reconhecida como direito público subjetivo, rompendo assim com a ideia de ensino supletivo, conforme observa Paiva (2009).

Entretanto, em que pesem as garantias constitucionais, tanto Paiva (2009) quanto Costa (2013) observam retrocessos no que diz respeito aos direitos, visto que a Emenda Constitucional 14/96 alterou o inciso I do Art. 208 da Constituição Federal, induzindo que o ensino fundamental possa atender aos jovens e adultos, mas não em caráter de obrigatoriedade, sob o argumento de que não se podem obrigar adultos e jovens além dos 14 anos a frequentar a escola, se não o fizeram 
na idade própria . "Não resta dúvida de que a emenda 14/96 foi um duro golpe contra o processo inclusivo de jovens e adultos ao sistema educativo, uma vez que tirou o compromisso do Estado com essa população" (COSTA, 2013, p. 76).

Com a criação do Fundo de Manutenção e Desenvolvimento do Ensino Fundamental e de Valorização do Magistério (FUNDEF), o financiamento da educação foi focalizado no ensino fundamental, comprometendo outros níveis e modalidades de educação, como a infantil e a de jovens e adultos.

Em dezembro de 2006, na perspectiva de superar os impasses causados pelo FUNDEF, foi aprovada a Emenda Constitucional 53, que criou o Fundo de Manutenção e Desenvolvimento da Educação Básica e Valorização dos Profissionais da Educação (FUNDEB). Nesse sentido, partia-se do princípio de que o FUNDEB iria abranger todas as etapas e modalidades da educação básica, criando a expectativa de que a educação de jovens e adultos seria contemplada com financiamento específico e que os investimentos obedeceriam a critérios de equidade. Entretanto,

[...] isso não aconteceu, pois a Lei Federal $N^{\circ} 11.494 / 2007$, que regulamentou o FUNDEB, acabou oficializando a histórica discriminação sofrida pela EJA. Isso se explica porque o valor aluno/ano destinado à EJA em 2007 era de $\mathrm{R} \$$ 662,40, inferior $42,86 \%$ em relação ao aluno de ensino fundamental e $71,43 \%$ em relação ao aluno de ensino médio. Para sacramentar a injustiça oficial, a mesma lei estabeleceu ainda que a apropriação dos recursos do FUNDEB, em cada estado para a EJA, será de apenas $15 \%$ do total de recursos, que são explicitamente insuficientes para garantir um ensino de qualidade (COSTA, 2013, p. 79).

As limitações à educação de jovens e adultos também são identificadas no Plano Nacional de Educação (2001-2010). Inclusive, após os vetos presidenciais aos recursos em 2001, as metas e as diretrizes para essa modalidade educativa foram comprometidas no que diz respeito à construção social do direito, conforme observa Paiva (2009). Mesmo com o FUNDEB e com o debate sobre o novo Plano Nacional de Educação (2011-2020), os desafios ainda estão postos tanto aos processos de alfabetização e de letramento quanto de inserção ao mundo do trabalho de jovens e adultos no Brasil. Observamos assim que

O capítulo dedicado à EJA no PNE aprovado pelo Congresso na forma da Lei $\mathrm{n}$. 10.172/2001 teceu um diagnóstico que reconheceu a extensão do analfabetismo absoluto e funcional e sua desigual distribuição entre as zonas rural e urbana, as regiões brasileiras, os grupos de idade, sexo e etnia. O Plano admitia ser insuficiente apostar na dinâmica demográfica e atuar apenas junto às novas gerações, propondo que as ações de escolarização atingissem também os adultos e idosos. Nas diretrizes, o PNE aderiu à concepção de educação continuada ao longo da vida, mas priorizou a atenção ao direito público subjetivo dos jovens e adultos ao ensino fundamental público e gratuito (DI PIERRO, 2010, p. 944).

A autora destaca que as políticas públicas decorrentes do Plano Nacional de Educação (2011-2020) - o qual já deveria estar em vigor - devem conferir materialidade a ideias mais apropriadas de alfabetização e educação básica com qualidade social, implicando assim a necessidade de articular devidamente as oportunidades de qualificação profissional e de acesso às novas tecnologias da comunicação e da informação. Para tanto, é necessário ampliar o financiamento destinado à educação de jovens e adultos e superar a situação de despreparo e 
desvalorização profissional dos educadores que a ela se dedicam, bem como rever os currículos e as práticas pedagógicas voltadas a essa modalidade educativa.

Ainda no que diz respeito ao marco legal, ressaltamos também a aprovação das Diretrizes Curriculares Nacionais para a EJA, conforme o Parecer da Câmara de Educação Básica, no 11/2000, nas quais foram estabelecidas as três funções, quais sejam: reparadora, equalizadora e qualificadora, sendo esta última de extrema importância, superando assim o caráter compensatório na educação de jovens e adultos, além de retomar a ideia de educação permanente (CARVALHO, 2009).

\section{EDUCAÇÃO DE JOVENS E ADULTOS E EDUCAÇÃO PROFISSIONAL: UMA INTEGRAÇÃO POSSÍVEL?}

Nos anos 2000, as ações decorrentes do Plano de Desenvolvimento da Educação - PDE associadas às lutas e conquistas consolidadas na agenda governamental das políticas de educação ampliaram as possibilidades de inclusão da EJA no plano da educação profissional. Disso resultou, por exemplo, a implementação do Programa Nacional de Integração da Educação Profissional com a Educação Básica na Modalidade de Educação de Jovens e Adultos (PROEJA), sendo instituído por meio do Decreto n. 5.840, de 13 de julho de 2006, conforme mostra Moura (2008). Tendo como objetivo se constituir em uma política de inclusão social emancipatória, parte da compreensão de que a escola é um locus integrante e atuante nas dinâmicas sociais, devendo contribuir para o desenvolvimento das vocações produtivas e das potencialidades de desenvolvimento regional, envolvida em ações de sustentabilidade sociocultural, econômica e ambiental.

Pretende, ainda, do ponto de vista político-governamental, oferecer as condições para a inclusão da população em suas ofertas educacionais; inserção orgânica da modalidade de EJA integrada à educação profissional nos sistemas de educação públicos; ampliação do direito à educação básica, pela universalização do ensino médio; trabalho como princípio educativo; pesquisa como fundamento da formação; e condições geracionais, de gênero, das relações étnicoraciais como fundantes da formação humana e dos modos como se produzem as identidades sociais (BRASIL, 2006). Assim sendo,

\footnotetext{
Um dos grandes desafios do Programa é integrar três campos da educação que historicamente não estão muito próximos: o ensino médio, a formação profissional técnica de nível médio e a educação de jovens e adultos. Igualmente desafiante é conseguir fazer com que as ofertas resultantes do Programa efetivamente contribuam para a melhoria das condições de participação social, política, cultural e no mundo do trabalho desses coletivos, ao invés de produzir mais uma ação de contenção social. Coloca-se ainda outro desafio em um plano mais elevado: a transformação desse Programa em política educacional pública do estado brasileiro (MOURA, 2006, p. 02).
}

De fato, o PROEJA se constitui em um importante indicador de ações sistêmicas das políticas de educação para a modalidade de educação de jovens e adultos, tanto no que concerne à oferta quanto no que se refere às concepções e práticas dos profissionais que atuam nos processos de gestão e de ensino-aprendizagem. Ademais, desde 2009 o programa vem consolidando a produção de monografias e livros que discutem a problemática da educação profissional articulada à educação básica na modalidade de educação de jovens e adultos. 
Com a oferta do PROEJA, o Instituto Federal de Educação, Ciência e Tecnologia do Rio Grande do Norte vem desenvolvendo inúmeras ações tanto no que concerne aos cursos de ensino médio integrado quanto na Pós-Graduação lato sensu. Na região do Mato Grande, em particular, as ações desenvolvidas pelo IFRN/Campus João Câmara para a educação de jovens e adultos vêm se ampliando, sobretudo no contexto da diversidade, tendo em vista a pluralidade socioeconômica, política e cultural, decorrente da existência de comunidades quilombolas, indígenas, assentados, agricultores familiares, pescadores, etc.

Desde 2010, o Núcleo de Estudos em Educação e Diversidade (NEPED)/IFRN - Campus João Câmara e o Grupo de Estudos em Linguagem, Formação Profissional Docente e Inclusão Social GELFOPIS (IFRN/Campus Macau) vêm investindo em iniciativas de ensino, pesquisa e extensão voltadas para a EJA, destacando-se, além do PROEJA, os cursos de Pós-Graduação lato sensu: Especialização em Organização e gestão escolar para a educação do campo e educação de jovens e adultos (aprovada via MEC/DPEJA/SECADI/FNDE); Especialização em Educação, sustentabilidade e geografia do semiárido (aprovada pelo edital 35/2010 - CNPq - Linha Temática 4); Especialização em Educação do campo - saberes da terra (aprovada via MEC/SECADI/FNDE). No âmbito das atividades de extensão, o Campus João Câmara do IFRN também coordenou o Projeto Mulheres Mil, destinado à alfabetização e profissionalização de mulheres que moram nos assentamentos da região.

Esses cursos visam à melhoria da qualidade educativa para a modalidade de educação de jovens e adultos, principalmente porque ocorrem numa região onde se concentram os menores índices educativos do estado do Rio Grande do Norte. Além do Núcleo de Pesquisa, o Campus João Câmara também vem amadurecendo a proposta de criação e consolidação - a partir das experiências desenvolvidas - de um Centro de Referência em Educação e Diversidade, com a finalidade de oferecer formação continuada, aperfeiçoamentos, assessorias aos municípios da região, bem como a interação no campo acadêmico-científico no que concerne às pesquisas com enfoque nas ações voltadas à diversidade e à inclusão social.

\section{EDUCAÇÃO DE JOVENS E ADULTOS NO CONTEXTO DA DIVERSIDADE: CONSIDERAÇÕES SOBRE A REGIÃO DO MATO GRANDE}

Financiado pelo edital universal 2011 do Conselho Nacional de Desenvolvimento Científico e Tecnológico - CNPq, o NEPED/IFRN/Campus João Câmara desenvolveu pesquisa, sob a coordenação de Azevedo (2014), objetivando contribuir para o mapeamento de indicadores que visem à qualidade social para a educação de jovens e adultos no contexto da diversidade, tendo como parâmetro os programas e projetos voltados à educação de jovens e adultos no contexto da diversidade, com enfoque na escolarização e qualificação profissional, em funcionamento nos municípios investigados, os quais estão situados na Região do Mato Grande norte-rio-grandense.

A coleta dos dados foi realizada por meio de questionário e entrevistas semiestruturadas aplicados junto aos gestores e/ou coordenadores pedagógicos que atuam com a educação de jovens e adultos na região do Mato Grande, onde se localiza o Campus João Câmara do IFRN, cuja caracterização é descrita no Quadro 1: 
Quadro 1: Oferta da EJA nos sistemas oficiais de educação (estado e municípios) - região do Mato Grande - nos municípios investigados.

\begin{tabular}{|c|c|c|c|c|c|}
\hline DESCRITIVO & $\begin{array}{c}\text { João } \\
\text { Câmara }\end{array}$ & $\begin{array}{c}\text { Poço } \\
\text { Branco }\end{array}$ & Taipu & Touros & $\begin{array}{l}\text { São Miguel } \\
\text { do Gostoso }\end{array}$ \\
\hline $\begin{array}{l}\text { Quantidade de escolas ou estabelecimentos onde } \\
\text { funciona a EJA }\end{array}$ & 4 & 1 & 3 & 2 & 19 \\
\hline Matrícula total da EJA & 948 & 141 & 74 & 829 & 601 \\
\hline \multicolumn{6}{|c|}{ Escolas estaduais - urbanas } \\
\hline № de escolas & 2 & 2 & 1 & - & - \\
\hline № de turmas & 11 & - & 2 & - & - \\
\hline Turnos & $\mathrm{N}$ & - & $\mathrm{N}$ & - & - \\
\hline Total de matrícula & 332 & - & 74 & - & - \\
\hline Faixa etária & & - & $16-55$ & - & - \\
\hline Qte. de professores graduados na área da educação & 15 & - & 2 & - & - \\
\hline Qte. de professores sem a formação na área & 0 & - & - & - & - \\
\hline Qte. de professores só com ensino médio & - & - & - & - & - \\
\hline \multicolumn{6}{|c|}{ Escolas estaduais - rurais } \\
\hline № de escolas & - & - & - & - & - \\
\hline № de turmas & - & - & - & - & - \\
\hline Turnos & - & - & - & - & - \\
\hline Total de matrícula & - & - & - & - & - \\
\hline Faixa etária & - & - & - & - & - \\
\hline Qte. de professores graduados na área da educação & - & - & - & - & - \\
\hline Qte. de professores sem a formação na área & - & - & - & - & - \\
\hline Qte. de professores só com ensino médio & - & - & - & - & - \\
\hline \multicolumn{6}{|c|}{ Escolas municipais - urbanas } \\
\hline № de escolas & - & 2 & 1 & 1 & 1 \\
\hline № de turmas & - & 5 & 1 & 11 & 4 \\
\hline Turnos & - & $\mathrm{N}$ & $\mathrm{N}$ & $\mathrm{N}$ & $\mathrm{N}$ \\
\hline Total de matrícula & - & 141 & 32 & 350 & 87 \\
\hline Faixa etária & - & $17-50$ & $16-55$ & $14-63$ & $12-80$ \\
\hline Qte. de professores graduados na área da educação & - & 3 & 1 & 11 & 2 \\
\hline Qte. de professores sem a formação na área & - & 1 & - & - & - \\
\hline Qte. de professores só com ensino médio & - & 1 & - & - & - \\
\hline \multicolumn{6}{|c|}{ Escolas municipais - rurais } \\
\hline № de escolas & - & 12 & 1 & 1 & 2 \\
\hline № de turmas & - & - & 2 & 2 & 3 \\
\hline Turnos & - & - & $\mathrm{N}$ & $\mathrm{N}$ & $\mathrm{N}$ \\
\hline Total de matrícula & - & - & 42 & 59 & 39 \\
\hline Faixa etária & - & - & - & $14-55$ & $12-80$ \\
\hline Qte. de professores graduados na área da educação & - & - & 1 & 3 & 6 \\
\hline Qte. de professores com especialização na área & - & - & - & - & - \\
\hline Qte. de professores só com ensino médio & - & - & 1 & - & - \\
\hline
\end{tabular}

Fonte: Dados da pesquisa

Ao analisarmos o quadro 1, percebemos que a maioria dos professores que atuam nos sistemas oficiais de educação possuem a formação inicial, mas a ausência de dados no item quantidade de professores sem especialização na área indica que a formação continuada é uma necessidade nos sistemas oficiais de educação, o que já é indicado em estudos como os de Dias (2011). Percebemos também que a faixa etária dos sujeitos é bastante diversa, merecendo maior atenção a ideia do direito à educação longa da vida, bem como a superação de alguns estereótipos 
que permeiam a EJA, como a concepção de que os jovens e adultos estão fora da idade própria de escolarização ou que não são estudantes regulares.

Observamos também que todas as ofertas da EJA nos municípios investigados se desenvolvem no turno noturno, reforçando assim a necessidade da garantia do direito à educação de jovens e adultos trabalhadores. Chama-nos a atenção o fato de o município de João Câmara não atender à EJA em escolas do campo. Embora não tenhamos coletado informações mais específicas, presumimos que possivelmente significativo contingente de jovens e adultos que moram em espaços rurais podem encontrar-se fora da escola por falta de atendimento in loco, 0 que já pode se constatar em estudos desenvolvidos pelo UNICEF (2012).

O Programa Brasil Alfabetizado é regido pela Lei no 10.880, de 09 de junho de 2004, e pela Lei no 11.507, de 20 de julho de 2007, tendo como objetivos:

Incentivar o reconhecimento da EJA como direito; induzir a institucionalização da educação de jovens e adultos como política pública; apoiar a ampliação da oferta e a melhoria da qualidade da educação de jovens e adultos na perspectiva da educação continuada, entendendo a aprendizagem como processo que se dá em diferentes espaços e em todas as dimensões da vida; promover e apoiar as diferentes formas de educação, formal e não formal, para jovens e adultos (BRASIL, 2001, p. 6).

Para atingi-los, a Diretoria de Políticas para a Educação de Jovens e Adultos, da Secretaria de Educação Continuada, Alfabetização, Diversidade e Inclusão, do Ministério da Educação, priorizou como foco os seguintes eixos: financiamento; oferta de formação qualificada; elaboração, produção e distribuição de materiais didáticos e literários; fomento a políticas de acesso à leitura e articulação das redes sociais. O programa foi lançado no segundo semestre de 2003, sob o argumento de que recolocaria a alfabetização de jovens e adultos como prioridade na agenda educacional do País. Com essa iniciativa, o governo federal assumiu para si a responsabilidade política e constitucional para a oferta de alfabetização de qualidade. Assim sendo, foi reforçada a concepção de que seja dever do Estado garantir a educação como direito de todos.

Contraditoriamente ao que ocorre nas escolas municipais e estaduais com as ofertas regulares, os resultados da pesquisa indicam deficiências na formação inicial dos profissionais que atuam junto ao Programa Brasil Alfabetizado nos municípios pesquisados. Em João Câmara, dos 80 professores que atuam no programa, 70 só possuem o ensino médio. Em Touros, nenhum dos profissionais tem graduação, possuindo apenas o ensino médio. Apenas em Poço Branco e Taipu o número de docentes graduados supera os que têm o ensino médio, mas a quantidade não é tão ampla quanto em João Câmara e Touros.

Tais constatações indicam que a formação inicial ainda é um desafio para o trabalho docente e que para a EJA, em particular, alguns programas como o Brasil Alfabetizado contratam profissionais sem a devida formação, podendo prejudicar o processo de ensino-aprendizagem. 
Quadro 2: Oferta do ProJovem Campo - Saberes da Terra

\begin{tabular}{|c|c|c|c|c|c|}
\hline & João Câmara & $\begin{array}{l}\text { Poço } \\
\text { Branco }\end{array}$ & Taipu & Touros & $\begin{array}{l}\text { São Miguel } \\
\text { do Gostoso }\end{array}$ \\
\hline № de turmas & 1 & - & - & - & - \\
\hline $\mathrm{N}^{\circ}$ de matrículas & 29 & - & - & - & - \\
\hline Onde funciona & $\begin{array}{l}\text { Comunidade Indígena - } \\
\text { Mendonça do Amarelão }\end{array}$ & - & - & - & - \\
\hline $\begin{array}{l}\text { Qte. de professores graduados na área } \\
\text { da educação }\end{array}$ & 3 & - & - & - & - \\
\hline $\begin{array}{l}\text { Qte. de professores sem a formação } \\
\text { na área }\end{array}$ & 1 & - & - & - & - \\
\hline Qte. de professores com ensino médio & - & - & - & - & - \\
\hline Proposta pedagógica & - & - & - & - & - \\
\hline Orientador do planejamento & Técnicos da SEEC/RN & - & - & - & - \\
\hline Material didático-pedagógico & - & - & - & - & - \\
\hline Fonte do material & - & - & - & - & - \\
\hline Como é usado & - & - & - & - & - \\
\hline
\end{tabular}

De acordo com os dados coletados pela pesquisa, o programa atende à comunidade indígena Mendonça do Amarelão, situada em João Câmara. O ProJovem Campo - Saberes da Terra é oriundo do Programa Saberes da Terra, criado em 2005, estando vinculado à SECADI/MEC. Visa à escolarização de 5.000 jovens agricultores(as) familiares, conforme definidos pela Lei 11.326/06, de diferentes estados e regiões do país. Inicialmente, o Programa Saberes da Terra estava presente em apenas algumas unidades da Federação, tais como Bahia, Pernambuco, Paraíba, Maranhão e Piauí, na região Nordeste; Mato Grosso do Sul, na região Centro-Oeste; Santa Catarina e Paraná, na região Sul; Minas Gerais, na região Sudeste; Pará, Tocantins e Rondônia, na região Norte.

Nos dois primeiros anos de sua existência, o Programa Saberes da Terra atuou em comunidades ribeirinhas, quilombolas, indígenas, assentamentos e em comunidades de pequenos agricultores. Escolarizou adultos e se manifestou em experiências pedagógicas, tais como "Encontros estaduais de educandos do Saberes da Terra", no Maranhão; "Pastas e utensílios da palha de bananeira", na Paraíba; "Projeto de produção agroecológica", no Pará; "Projeto Mandala", no Mato Grosso do Sul; "Noite da culinária camponesa" e "Projetos de vida dos educandos", no estado do Paraná; "Cadernos Pedagógicos", no Maranhão, Paraná e Tocantins.

O PNAD de 2006 indicou que de 6.276.104 jovens camponeses na faixa etária de 18 a 29 anos 1.641 .940 não concluíram o primeiro segmento do ensino fundamental, equivalente a $26,16 \%$, e 3.878 .757 (61,80\%) não concluíram sequer a segunda etapa do ensino fundamental. Para enfrentar esses índices alarmantes de exclusão educacional, houve um esforço conjunto entre - Ministério da Educação, por meio da Secretaria de Educação Continuada, Alfabetização e Diversidade (SECAD) e da Secretaria de Educação Profissional e Tecnológica (SETEC), o Ministério do Desenvolvimento Agrário, por meio da Secretaria de Agricultura Familiar (SAF) e da Secretaria de Desenvolvimento Territorial (SDT), o Ministério do Trabalho e Emprego, por meio da Secretaria de Políticas Públicas de Emprego (SPPE) e da Secretaria Nacional de Economia Solidária (SENAES), o Ministério do Meio Ambiente, por meio da Secretaria de Biodiversidade e Floresta (SBF), o Ministério do Desenvolvimento Social e Combate à Fome (MDS) e a Secretaria Nacional de Juventude (SNJ), vinculada à Presidência da República, e, mediante a Medida Provisória no 411/07, o Programa Saberes da Terra passou a integrar a Política Nacional de Inclusão de Jovens - 
ProJovem, passando a ser denominado de "ProJovem Campo - Saberes da Terra", com objetivo explícito de promover a reintegração do jovem ao processo educacional, sua qualificação profissional e seu desenvolvimento humano.

Em que pese haver respaldo governamental acerca do programa e de o Documento Nacional Preparatório da VI Conferência Nacional de Educação de Jovens e Adultos - CONFINTEA, realizada em dezembro de 2009, em Belém do Pará, reconhecer a iniciativa como uma das ações estratégicas para a alfabetização de adultos, percebemos, à luz do quadro 2, que as ações decorrentes do Brasil Alfabetizado são realizadas em espaços não escolares, como associações e assentamentos, não havendo acompanhamento sistemático por parte dos sistemas oficiais de educação, indicando assim que o programa pode ter comprometimento de ordem didáticopedagógica, como a falta de orientação didático-pedagógica, formação inicial e continuada e condições de trabalho, o que já pode ser identificado nos estudos de Lima (2012), ao analisar o programa em município da região do Mato Grande.

\section{CONSIDERAÇÕES FINAIS}

Vimos que a implantação do Campus João Câmara do Instituto Federal de Educação, Ciência e Tecnologia do Rio Grande do Norte, situado na região do Mato Grande, vem contribuindo com diversas ações voltadas ao ensino, como os cursos do PROEJA; de pesquisa, como as atividades do NEPED, que resultaram no fomento da pesquisa financiada pelo CNPq; e de extensão, como a oferta do Programa Mulheres Mil.

Por outro lado, alguns programas governamentais implementados naquela região, como o ProJovem Campo e o Brasil Alfabetizado, que visam atender aos jovens e adultos na perspectiva da alfabetização ou da qualificação profissional, enfrentam inúmeros desafios na sua execução, como a falta de acompanhamento e de avaliação, problemas de infraestrutura física e material, bem como na seleção e no perfil do corpo docente que atuam nos respectivos programas.

Em tempos de caminhos e descaminhos no contexto da política educacional brasileira, sobretudo no que diz respeito ao Plano Nacional de Educação e do discurso e das lutas por um sistema articulado que garanta a educação como um direito pleno e de qualidade socialmente referenciada, a educação profissional e a educação de jovens e adultos situam-se num contexto marcado por desafios no que diz respeito à educação e ao trabalho, sobretudo mediante os altos índices de analfabetismo e da necessidade de qualificação como um dos importantes componentes de inserção ao mundo do trabalho.

\section{REFERÊNCIAS BIBLIOGRÁFICAS}

1. ARROYO, Miguel. Introdução: os coletivos diversos repolitizam a formação. In: DINIZ-PEREIRA, Júlio Emílio; LEÃO, Geraldo (Org.). Quando a diversidade interroga a formação docente. Belo Horizonte: Autêntica, 2008.

2. AZEVEDO, Márcio Adriano de (Coord.). Indicadores para a qualidade social na educação de jovens e adultos no contexto da diversidade: relatório técnico-científico. João Câmara: CNPq/NEPED-IFRN, 2014.

3. ; SILVA, Lenina Lopes S. Reforma educativa a partir dos anos 1990: implementação na 
América Latina, Caribe e particularidades brasileiras. Holos, Natal/RN, v. 2, ano 28, p. 250-260, maio 2012. Disponível em: <http://www2.ifrn.edu.br/ojs/index.php/HOLOS/article/view/ 928/548>. Acesso em: jun. 2012.

4. BRASIL. Lei de Diretrizes e Bases da Educação Nacional. n. 9.394/96, de 20 de dezembro de 1996. Diário Oficial [da] República Federativa do Brasil, Poder Executivo, Brasília-DF, 23 dez. 1996. Seção 1, p. 27.833-27.841.

5. _. Lei n. 11.892, de 29 de dezembro de 2008. Institui a Rede Federal de Educação Profissional, Científica e Tecnológica, cria os Institutos Federais de Educação, Ciência e Tecnologia, e dá outras providências. Disponível em:<http://www.planalto.gov.br/ccivil_03 /_Ato2007-2010/2008/Lei/L11892.htm>. Acesso em: 20 dez. 2011.

6. COSTA, Antônio Cláudio Moreira. Educação de jovens e adultos no Brasil: novos programas, velhos problemas. Disponível em:< http://www.utp.br/cadernos_de_pesquisa/pdfs/cad_ pesq8/4_educacao_jovens_cp8.pdf>. Acesso em: 20 jul. 2013.

7. DELORS, Jacques (Coord.). Educação: um tesouro a descobrir. 8. ed. Brasília: Cortez, 2003.

8. DIAS, Rosimeri de Oliveira. Deslocamentos na formação de professores: aprendizagem de adultos, experiência e políticas cognitivas. Rio de Janeiro: Lamparina, 2011.

9. DI PIERRO, M. Clara. A educação de jovens e adultos no Plano Nacional de Educação: avaliação, desafios e perspectivas. Educação e sociedade, Campinas, v. 31, n. 112, p. 939-959, jul.-set. 2010.

10. FREIRE, Paulo. Pedagogia do oprimido. 50. ed. rev. e atual. Rio de Janeiro: Paz e Terra, 2011.

11. FRIGOTTO, Gaudêncio; CIAVATTA, Maria; RAMOS, Marise (Org.). Ensino médio integrado: concepções e contradições. São Paulo: Cortez, 2005.

12. GADOTTI, Moacir. Educação de Jovens e Adultos: correntes e tendências. In: ; ROMÃO, José Eustáquio (Org.). Educação de Jovens e Adultos: teoria, prática e proposta. 4. ed. São Paulo: Cortez, 2001. p. 29-40. (Coleção Escola Cidadã, v. 5).

13. GAJARDO, Marcela. Reformas educativas em América Latina: balance de uma década. OPREAL, [s.I.], n. 15. set. 1999.

14. LIMA, Adriana Mônica Oliveira Ponciano de. Tecendo saberes na educação de jovens e adultos: olhares sobre o município de Pureza/RN. João Câmara, 2012, 104 f. Monografia (Especialização em Organização e Gestão para as modalidades de Educação de Jovens e Adultos e Educação do Campo)-Instituto Federal de Educação, Ciência e Tecnologia do Rio Grande do Norte, Campus João Câmara, 2012.

15. LIMA, Licínio C. Educação ao longo da vida: entre a mão direita e a mão esquerda de Miro. São Paulo: Cortez, 2007.

16. MOURA, Dante Henrique. A implantação do PROEJA no CEFET-RN: avanços e retrocessos. Natal: Mimeo, 2008.

17. __ Educação básica e educação profissional tecnológica: dualidade histórica e perspectivas de integração. In: 1a CONFERÊNCIA NACIONAL DE EDUCAÇÃO PROFISSIONAL E TECNOLÓGICA, Brasília: 2006. No prelo.

18. PACHECO, Eliezer. Os institutos federais: uma revolução na educação profissional e tecnológica. Natal: IFRN, 2010. 
19. PAIVA, Jane. Direito formal e realidade social da educação de jovens e adultos. In: SAMPAIO, Marisa Narciso; ALMEIDA, Rosilene Souza (Org.). Práticas de educação de jovens e adultos: complexidades, desafios e propostas. Belo Horizonte: Autêntica, 2009. p. 21-64. (Coleção Estudos em EJA).

20. PRADO, Edna Cristina do. Políticas públicas federais para a educação de jovens e adultos: um olhar sobre a reforma dos anos 90 . In: ; MELO, Adriana Almeida Sales de (Org.). Educação, história, política e educação de jovens e adultos. Maceió: EDUFAL, 2012. p. 77-94.

21. TAVARES, Andrezza Maria Batista do Nascimento. O pedagogo como agente de transformação social para além dos muros escolares. 265 p. Tese (Doutorado em Educação)Programa de Pós-Graduação em Educação, Centro de Ciências Sociais Aplicadas, Universidade Federal do Rio Grande do Norte, Natal, 2010.

22. UNICEF. Fundo das Nações Unidas para a Infância. Acesso, permanência, aprendizagem e conclusão da educação básica na idade certa - Direito de todas e de cada uma das crianças e dos adolescentes. Brasília: UNICEF, 2012. 